\title{
Online Service Quality of the B2C e-commerce Companies in China
}

\author{
Yonglin Liang ${ }^{1}$ and Shumei $\mathrm{Liu}^{2}$ \\ ${ }^{1}$ College of Computer Science, Shaoguan University \\ Daxue Street, Zhenjiang District, Shaoguan \\ ${ }^{2}$ Center of Modern Educational Technology, Hengshui University \\ Heping West Road, Taocheng District, Hengshui
}

${ }^{1}$ liangyonglin@126.com, ${ }^{2}$ lsm-key@163.com

\begin{abstract}
The measurement of online service quality has become increasing important as the ecommerce companies deliver an expanding array of service through the websites. There are few quantitative studies on the online service quality as sessment focused on the market in China, which is one of the developing countries with the highest ontine population growth. This paper is an attempt to identify the measurement of the online service quality in China, and grey approach is applied to identify the riteria of online service quality assessment. The results could be the guideline for the e-commerce companies in terms of improving their service.
\end{abstract}

Keywords: Leading industries, Environmental factor, Grey approach, Sustainable development.

\section{Introduction}

As the development of the internet, there are increasingly users in the world engaging in ecommerce activities. As is know to all, China is one of the developing countries with the highest online population growth rates. With the development of the e-commerce, an increasing number of customers have used the e-commerce websites to obtain the related information about products and services, with possible follow-up purchase (Korner and Zimmerman, 2000; Geissler, 2001).The measurement and evaluation of the online service quality is becoming increasing important as the e-commerce companies deliver an expanding array of services through the internet, in which the websites clearly emerge as a critical channel for e-commerce companies.

It is necessary for the e-commerce companies to identify customers' needs, wants, and preferences in order to deliver high quality service performance (Howard and Worboys, 2003). Effective measurements are indispensable; several measurement scales and their extensions prevail, though most originally stemmed from conventional, face-to-face service contexts (Kassim and Bojeib, 2002; Kettinger et al., 1995; Pitt et al., 1995). However, the service environment differs a lot between the physical stores and online storefronts, so it is necessary to study the online service quality.

This paper is an attempt to identify the main factors affecting online service quality for the e-commerce companies in China, which could be the guideline for the development of the companies. The remainder of this study is organized as follows. Section 2 introduces the related literature about the online service quality. Following is a brief introduction about the 
Grey approach which is employed in this research. Section 4 discusses the main factors that have an impact on the online service, and illustrate an empirical analysis of $18 \mathrm{~B} 2 \mathrm{C}$ ecommerce websites in China. In the last section, the related managerial implications of this research are discussed.

\section{Literature Review}

Consumers usually evaluate e-commerce companies based on the perceived online service quality and satisfaction (Peterson and Wilson, 1992). Service quality remains of focal interest to researchers and practitioners. Many researchers consider service quality a measure of how well the delivered service level meets the customer's expectation. Compared with the abundant research examining the quality of face-to-face services, investigations of online service quality remain in their infancy (Serkan et al., 2010).

A handful of scales measure web site quality (Loiacono et al., 2002; Yoo and Donthu, 2001), online service quality (Bauer et al., 2006; Parasuraman et al., 2005; Zeithaml et al., 2000), or e-retailing quality (Wolfinbarger and Gilly, 2003). In general, these scales derive from rigorous development efforts and focus on important characteristics pertaining to information or the system; few consider the service dimension of online services comprehensively (Nelson et al., 2005; Wixom and Todd, 2005) Table 1 summarizes the related research results:

Table 1. Online service quality scales in prior related research

\begin{tabular}{|c|c|c|}
\hline Article & System related & Service related \\
\hline $\begin{array}{l}\text { Zeithaml et al. } \\
(2000)\end{array}$ & $\begin{array}{l}\text { Access, ease of navigation, flexibility, reliability, price } \\
\text { knowledge, aesthetics, efficiency, personal/zation, privacy. }\end{array}$ & $\begin{array}{l}\text { Responsiveness, } \\
\text { assurance }\end{array}$ \\
\hline $\begin{array}{l}\text { Francis and White } \\
(2002)\end{array}$ & $\begin{array}{l}\text { Product attribute, functionality, ownership conditions, } \\
\text { security }\end{array}$ & $\begin{array}{l}\text { Delivery, customer } \\
\text { service }\end{array}$ \\
\hline $\begin{array}{l}\text { Loiacono et al. } \\
(2002)\end{array}$ & $\begin{array}{l}\text { Appeal, response tine flow, image, operations, better than } \\
\text { alternatives, inno vativeness, interact vity, trust }\end{array}$ & \\
\hline $\begin{array}{l}\text { Barnes and } \\
\text { Vidgen (2002) }\end{array}$ & Usability, design & Empathy, trust \\
\hline $\begin{array}{l}\text { Wolfinbarger and } \\
\text { Gilly (2003) }\end{array}$ & privacy & $\begin{array}{l}\text { Fulfillment/reliability, } \\
\text { customer service }\end{array}$ \\
\hline $\begin{array}{l}\text { Parasuraman et a } \\
(2005)\end{array}$ & oility, privacy & Fulfillment \\
\hline $\begin{array}{l}\text { Parasuraman et at } \\
(2005)\end{array}$ & & $\begin{array}{l}\text { Compensation, } \\
\text { responsiveness contract }\end{array}$ \\
\hline $\begin{array}{l}\text { Bauer et al. } \\
(2006)\end{array}$ & Reliability, process, functionality/design & $\begin{array}{l}\text { Responsiveness, } \\
\text { enjoyment }\end{array}$ \\
\hline $\begin{array}{l}\text { Yoo and Donthu } \\
\text { (2001) }\end{array}$ & Ease of use, aesthetic design, reliability, tangibles & Responsiveness \\
\hline $\begin{array}{l}\text { Aldwani and } \\
\text { Palvia }(2002) \\
\end{array}$ & $\begin{array}{l}\text { Technical adequacy, specific content, content quality, web } \\
\text { appearance }\end{array}$ & \\
\hline Janda et al. (2002) & Access, security, information & Sensation \\
\hline Li etah (2002) & $\begin{array}{l}\text { Competence, quality of information, web assistance, } \\
\text { empathy }\end{array}$ & $\begin{array}{l}\text { Responsiveness, call- } \\
\text { back systems }\end{array}$ \\
\hline $\begin{array}{l}\text { Ranganathan and } \\
\text { Ganapathy (2002) }\end{array}$ & Information content, design, security, privacy & \\
\hline $\begin{array}{l}\text { Yang and Jun } \\
(2002)\end{array}$ & Reliability, access, ease of use, personalization, security & Responsiveness \\
\hline $\begin{array}{l}\text { Cai and Jun } \\
(2003)\end{array}$ & Website design/content & $\begin{array}{l}\text { Trustworthiness, } \\
\text { prompt/reliable service, } \\
\text { communication }\end{array}$ \\
\hline $\begin{array}{l}\text { Gounaris and } \\
\text { Dimitriadis } \\
(2003)\end{array}$ & & $\begin{array}{l}\text { Customer care and risk } \\
\text { reduction benefit, } \\
\text { information benefit, }\end{array}$ \\
\hline
\end{tabular}




\begin{tabular}{|c|c|c|}
\hline & & interaction facilitation \\
\hline Jun et al. (2004) & Ease of use, attentiveness, access, security, credibility & $\begin{array}{l}\text { Reliable/prompt } \\
\text { responses }\end{array}$ \\
\hline $\begin{array}{l}\text { Kim and Stoel } \\
(2004)\end{array}$ & $\begin{array}{l}\text { Web appearance, entertainment, information fit-to-task, } \\
\text { transaction capacity }\end{array}$ & Response time, trust \\
\hline $\begin{array}{l}\text { Lee and Lin } \\
(2005)\end{array}$ & Website design, reliability, personalization & Responsiveness, trust \\
\hline $\begin{array}{l}\text { Parasuraman et al. } \\
\text { (2005) }\end{array}$ & Efficiency, system availability, privacy & Fulfillment \\
\hline Yang et al. (2005) & $\begin{array}{l}\text { Usability, usefulness of content, adequacy of information, } \\
\text { accessibility }\end{array}$ & Interaction \\
\hline $\begin{array}{l}\text { Bauer } \text { et al. } \\
(2005)\end{array}$ & Functionality/design, process, reliability & $\begin{array}{l}\text { Enjoyment, } \\
\text { responsiveness }\end{array}$ \\
\hline $\begin{array}{l}\text { Collier and } \\
\text { Bienstock (2006) }\end{array}$ & $\begin{array}{l}\text { Functionality, information accuracy, design, privacy, ease of } \\
\text { use, order condition, order accuracy, procedural fairness, } \\
\text { outcome fairness }\end{array}$ & $\begin{array}{l}\text { Timeliness, interactive } \\
\text { fairness }\end{array}$ \\
\hline $\begin{array}{l}\text { Ibrahim et al. } \\
\text { (2006) }\end{array}$ & $\begin{array}{l}\text { Convenience/accuracy, accessibility/reliability, good queue } \\
\text { management, personalization }\end{array}$ & $\begin{array}{l}\text { Friendly/responsive } \\
\text { customer service, } \\
\text { argeted customer } \\
\text { service }\end{array}$ \\
\hline $\begin{array}{l}\text { Cristobal et al. } \\
(2007)\end{array}$ & Web design, assurance & Customer service \\
\hline $\begin{array}{l}\text { Ho and Lee } \\
(2007)\end{array}$ & Information quality, security, website functionality & $\begin{array}{l}\text { Customer relationships, } \\
\text { responsiveness }\end{array}$ \\
\hline $\begin{array}{l}\text { Sohn and Tadisina } \\
(2008)\end{array}$ & $\begin{array}{l}\text { Trust, ease of use, website con } \\
\text { reliability }\end{array}$ & $\begin{array}{l}\text { Customized } \\
\text { communication, speed } \\
\text { of delivery }\end{array}$ \\
\hline $\begin{array}{l}\text { Wang et al. } \\
(2010)\end{array}$ & $\begin{array}{l}\text { Reliability, competence } \\
\text { security }\end{array}$ & $\begin{array}{l}\text { Responsiveness, } \\
\text { satisfaction }\end{array}$ \\
\hline Ding et al. (2011) & Perceived control & $\begin{array}{l}\text { Service convenience, } \\
\text { customer service, } \\
\text { fulfillment }\end{array}$ \\
\hline
\end{tabular}

\section{Methodology}

\subsection{Grey system theory}

Grey system theory which can help evaluate outcomes under the situation with incomplete and indeterminate information is first proposed in 1982 (Deng, 1982). To introduce some fundamental aspects of grey stem theory, some basic definitions and notation are shown as follows:

$x$ is denoted as a close $l$ and bounded set of real numbers. A grey number, $\otimes x$, is defined as an interval with-known upper and lower bounds but unknown distribution information for $x$ (Deng, 1989), which is,

$$
\otimes x=[\otimes x, \otimes-x]=\left[x^{\prime} \in x \mid \otimes x \leq x^{\prime} \leq \bar{\otimes} x\right]
$$

where $\otimes x$ and $\bar{\otimes} x$ are the lower and upper bounds of $\otimes x$ respectively.

Expression (2) - (5) demonstrate some basic grey number mathematical operations:

$$
\begin{aligned}
& \otimes x_{1}+\otimes x_{2}=\left[\underline{x_{1}}+\underline{x_{2}}, \overline{x_{1}}+\overline{x_{2}}\right] \\
& \otimes x_{1}-\otimes x_{2}=\left[\underline{x_{1}}-\overline{x_{2}}, \overline{x_{1}}-\underline{x_{2}}\right] \\
& \otimes x_{1} \times \otimes x_{2}=\left[\min \left(\underline{x_{1}} \underline{x_{2}}, \underline{x_{1}} \overline{x_{2}}, \overline{x_{1}} \underline{x_{2}}, \overline{x_{1}} \overline{x_{2}}\right), \max \left(\underline{x_{1}} \underline{x_{2}}, \underline{x_{1}} \overline{x_{2}}, \overline{x_{1}} \underline{x_{2}}, \overline{x_{1}} \overline{x_{2}}\right)\right] \\
& \otimes x_{1} \div \otimes x_{2}=\left[\underline{x_{1}}, \overline{x_{1}}\right] \times\left[\frac{1}{x_{2}}, \underline{\frac{1}{x_{2}}}\right]
\end{aligned}
$$




\subsection{GRA (Grey Relational Analysis)}

Below is a briefly review of relevant definitions and the calculation procedure for the GRA approach.

GRA uses several small sub-problems to present the decision problem, and the problem is decomposed into a hierarchy with a goal at the top, criteria and sub-criteria at levels and sublevels and decision alternatives at the bottom of the hierarchy.

The comparison matrix involves the comparison in pairs of the elements of constructed hierarchy. The aim is to set their relative priorities with respect to each of the elements at the next higher level.

$$
\begin{aligned}
& \begin{array}{llllll}
C_{1} & C_{2} & C_{3} & \cdots & C_{n}
\end{array} \\
& D=\begin{array}{c}
C_{1} \\
C_{2}
\end{array} C_{3} \begin{array}{ccccc}
x_{11} & x_{12} & x_{13} & \cdots & x_{1 n} \\
C_{21} & x_{22} & x_{23} & \cdots & x_{2 n}
\end{array} \mid
\end{aligned}
$$

Where $x_{i j}$ is the degree preference of $i^{\text {th }}$ year over $j^{\text {th }}$ criterion. Before the calculation of vector of priorities, the comparison matrix has to be hormalized into the range of $[0,1]$ by the equation below:

The larger, the better type (Yang and Hung, 2007):

$$
y_{i j}=\frac{\left[x_{i j}-\min \left\{x_{i j}\right\}\right]}{\left[\max \left\{x_{i j}\right\}-\min \left\{x_{i j}\right\}\right]}
$$

The smaller, the better type:

$$
y_{i j}=\frac{\left[\max \left\{x_{i j}\right\}-x_{i j}\right]}{\left[\max \left\{x_{i j}\right\}-\min \left\{x_{i j}\right\}\right]}
$$

The normalized decision matrix IS denoted by $Y=\left[y_{i j}\right]_{m \times n}$.

Assume $\mathrm{Y}$ is a factor sefor grey correlation. Let $y_{0}(k)$ and $y_{i}(k)$ denote the initial criteria values of $y_{0}$ and $y_{i}$ on company k respectively.

As average correration value $r\left(y_{0}, y_{i}\right)$ of $\left\{r\left(y_{0}(k), y_{i}(k)\right) \mid k=1,2, \ldots, m\right\}$ is a real number, the value can be defined by grey correlation.

$$
\begin{aligned}
& \text { Let } r\left(y_{0}, y=\frac{1}{m} \sum_{k=1}^{m} r\left(y_{0}(k), y_{i}(k)\right)=r_{0 i}\right. \text {, where } \\
& \left.r(y), y_{i}(k)\right)=\frac{\min _{i} \min _{k}\left|y_{0}(k)-y_{i}(k)\right|+\rho \max _{i} \max _{k}\left|y_{0}(k)-y_{i}(k)\right|}{\left|y_{0}(k)-y_{i}(k)\right|+\rho \max _{i} \max _{k}\left|y_{0}(k)-y_{i}(k)\right|} \text {, where } \rho \text { is the }
\end{aligned}
$$

distinguished coefficient $(\rho \in[0,1])$.

Grey correlation matrix $R=\left(r_{i j}\right)$ is derived by grey correlation analysis, where $i=1,2, \ldots$, $m, j=1,2, \ldots, n$. The definition of clustering financial ratios based on the entries of the grey correlation matrix is presented as follows.

Definition 1: If $r_{i j} \geq r$ and $r_{j i} \geq r, Y_{i}$ and $Y_{j}$ belong to the same cluster, where $\mathrm{r}$ is a threshold value of clustering. 
Definition 2: If $r_{i j} \geq r, r_{j i} \geq r, r_{i k} \geq r$ and $r_{k i} \geq r$, but $r_{j k}<r$ or $r_{k j}<r$, if $\min \left\{r_{i j}, r_{i j}\right\} \geq \min \left\{r_{k i}\right.$, $\left.r_{i k}\right\}$, then $Y_{i}, Y_{j}$ and $Y_{k}$ belong to the same cluster.

As those indices can be partitioned into several clusters, the finding of representative indices of clusters is stated as follows.

Definition 3: If $Y_{i}$ and $Y_{j}$ belong to the one cluster, the representative index of the cluster is determined according to the maximum value of $r_{i j}$ and $r_{j i}$. If $r_{i j} \geq r_{j i}$, the representative index of the cluster is financial ratio $i$.

Definition 4: If $Y_{i}, Y_{j}$ and $Y_{k}$ are in the one cluster, the representati88888888888ve index of the cluster is decided according to the maximum value of $r_{i j}+r_{i k}, r_{j i}+r_{j k}$ and $r_{k i}+r_{k j}$. If $r_{i j}+$ $r_{j k}$ is the maximum value, then the representative index of the cluster is financial ratio $i$.

\subsection{The grey approach}

The grey approach is appropriate for solving the group decision-making problem in an uncertain environment. Let $A=\left\{A_{1}, A_{2}, \cdots A_{m}\right\}$ is a discrete set of $m$ leading industry alternatives. $\otimes w=\left\{\otimes w_{1}, \otimes w_{2}, \cdots \otimes w_{n}\right\}$ is the vector of criteria weights. Linguistic variables (Li et al., 2007) are adopted in this research, as shown in Table 1:

Table 1. Scale of Attribute Weights

\begin{tabular}{lcc}
\hline Rank & Sub-criteria grade & Membership function \\
\hline Very Low (VL) & 1 & {$[0.00,0.10]$} \\
Low (L) & 2 & {$[0.10,0.30]$} \\
Medium Low (ML) & 3 & {$[0.30,0.40]$} \\
Medium (M) & 4 & {$[0.40,0.50]$} \\
Medium High (MH) & 5 & {$[0.50,0.60]$} \\
High (H) & 6 & {$[0.60,0.90]$} \\
Very High (VH) & 7 & {$[0.90,1.00]$} \\
\hline
\end{tabular}

The criteria rating value is shown in table 2.

\section{Table 2. Scale of Attribute Weights}

\begin{tabular}{lcc}
\hline Rank & Sub-criteria grade & Membership function \\
\hline Very Poof (VP) & & {$[0.00,1.00]$} \\
Poor (P) & 2 & {$[0.10,0.30]$} \\
Medium Low (Mt) & 3 & {$[0.30,0.40]$} \\
Medium (M) & 4 & {$[0.40,0.50]$} \\
Medium High (MH) & 5 & {$[0.50,0.60]$} \\
High (H) & 6 & {$[0.60,0.90]$} \\
Very High (VH) & 7 & {$[0.90,1.00]$} \\
\hline
\end{tabular}

The detailed procedure is summarized as follows:

Step 1. Criteria weight identification

If the decision maker group has $\mathrm{K}$ raters, then the criteria weight is calculated using:

$\otimes w_{j}=\frac{1}{K}\left[\otimes w_{j}^{1}+\otimes w_{j}^{2}+\cdots \otimes w_{j}^{K}\right]$

Where $\otimes w_{j}^{K}(j=1,2, \cdots, n)$ is the criteria weight of $K^{\text {th }}$ rater and can be described by Grey number $\otimes w_{j}^{K}=\left[\underline{w}_{j}^{K}, \bar{w}_{j}^{K}\right]$.

Step 2: Criteria rating value in linguistic variables

Criteria rating value in linguistic variables are calculated using 


$$
\otimes Y_{i j}=\frac{1}{K}\left[\otimes Y_{i j}^{1}+\otimes Y_{i j}^{2}+\cdots \otimes Y_{i j}{ }^{K}\right]
$$

Where $\otimes Y_{i j}{ }^{K}(i=1,2, \cdots, m ; j=1,2, \cdots, n)$ is the criteria weight of $K^{\text {th }}$ rater and can be described by Grey number $\otimes Y_{i j}^{K}=\left[\underline{Y}_{i j}^{K}, \bar{Y}_{i j}^{K}\right]$.

Step 3: Establish the normalized grey decision matrix:

Since we had already normalized the decision matrix in the GRA process, then we should transfer the normalized numbers in the decision matrix into Grey numbers.

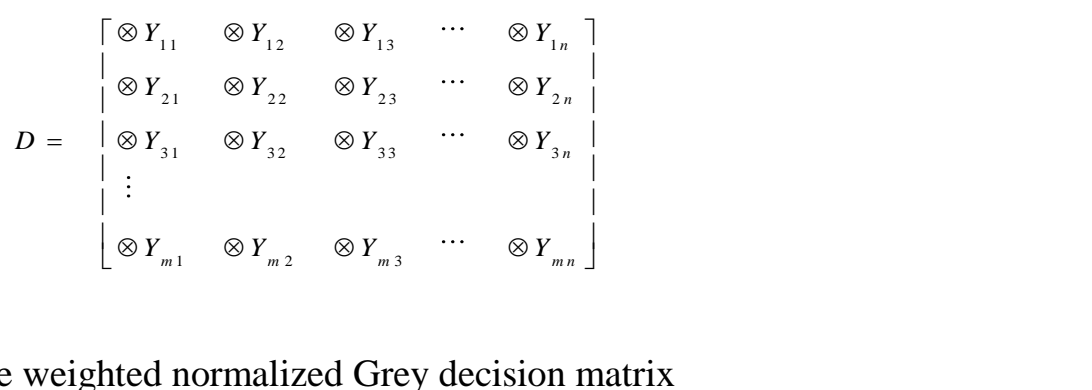

Step 4: Establish the weighted normalized Grey decision matrix

The weighted normalized Grey decision mafrix can be derived by the normalized Grey decision matrix and criteria weights by the equation as follows:

$\otimes V_{i j}=\otimes Y_{\mathrm{ij}} \times \otimes W_{j}$

Then the weighted normalized Grey decision matrix can be established as follows:

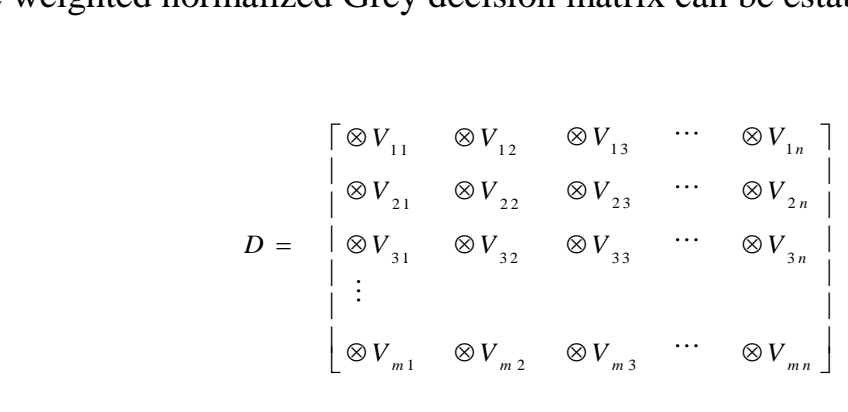

Step 5: Set ideal solution for the alternatives

$$
S^{\max }=\left\{\left[\max _{1 \leq i \leq a} \max _{1 \leq i \leq m} \bar{V}_{i 1}\right],\left[\max _{1 \leq i \leq m} V_{i 2}, \max _{1 \leq i \leq m} \bar{V}_{i 2}\right], \cdots,\left[\max _{1 \leq i \leq m} V_{-i n}, \max _{1 \leq i \leq m} \bar{V}_{i n}\right]\right\}
$$

Step 6: Calculate the Grey possibility

Compare the alternatives set $A=\left\{A_{1}, A_{2}, \cdots A_{m}\right\}$ with the ideal solution $A^{\text {max }}$ :

$\left.P A_{i} \leq A^{\max }\right\}=\frac{1}{n} \sum_{j=1}^{n}\left\{\otimes V_{i j} \leq \otimes Y_{j}^{\max }\right\}$

Step 7: Prioritize the industries

Sort the alternative industries based on $P\left\{A_{i} \leq A^{\mathrm{max}}\right\}$ comparison. If $A_{i}$ value is smaller, the ranking order of $A_{i}$ is better. Otherwise, the ranking order is worse.

\section{Data Collection and Results Analysis}


Considering the differences among B2C, C2C and B2B e-commerce, and our research is focus on $\mathrm{B} 2 \mathrm{C}$ e-commerce in China, the $18 \mathrm{~B} 2 \mathrm{C}$ e-commerce websites in retail market shown in table 3 are selected based on the user coverage.

\section{Table 3. $18 \mathrm{~B} 2 \mathrm{C}$ e-commerce websites in retail market in China}

\begin{tabular}{|l|l|c|}
\hline No. $\quad$ E-Commerce Website & No. of users (per million) \\
\hline 1 & Tmall & 9010 \\
2 & Jingdong Mall & 6940 \\
3 & Tencent & 3930 \\
4 & Amazon & 3450 \\
5 & Handle group buying & 2580 \\
6 & Dangdang & 2160 \\
7 & Vancl & 2160 \\
8 & Full King & 1290 \\
9 & No.1 & 1050 \\
10 & F group buying & 770 \\
11 & Yixun & 760 \\
12 & Moonbasa & 700 \\
13 & Letao & 640 \\
14 & Newegg & 600 \\
15 & M18 & 570 \\
16 & Okbuy & 560 \\
17 & VIPshop & 490 \\
18 & Mbaobao & 450 \\
\hline
\end{tabular}

The specific original measures are listed in Table 3. The decision problem consists of three levels: the objective of the problem is the highest level, while in the second level, the criteria are listed, and the sub-criteria are listed in the thi d level.

Table 3. The original measures of online service quality assessment

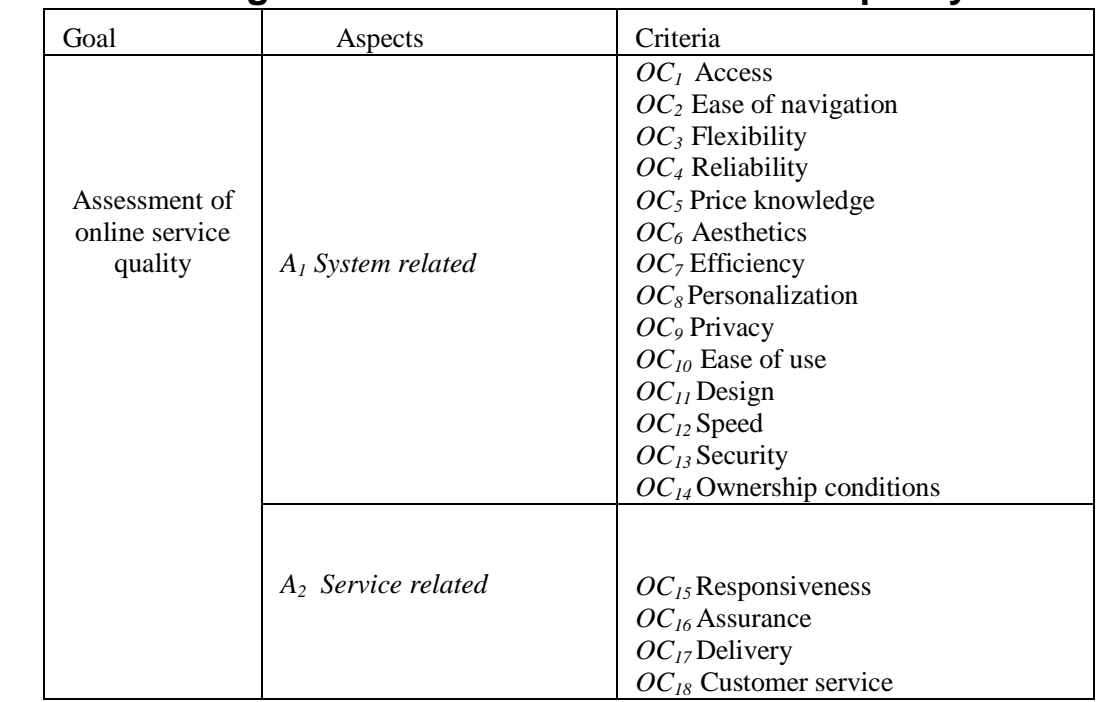

As-shown in Table 3, there are thirteen original measures, so GRA is employed for the representative selection. Grey Correlation matrix is derived from the DPS 9.0 (software which can determine the grey correlation matrix) as below (He and Zhai, 2009): 


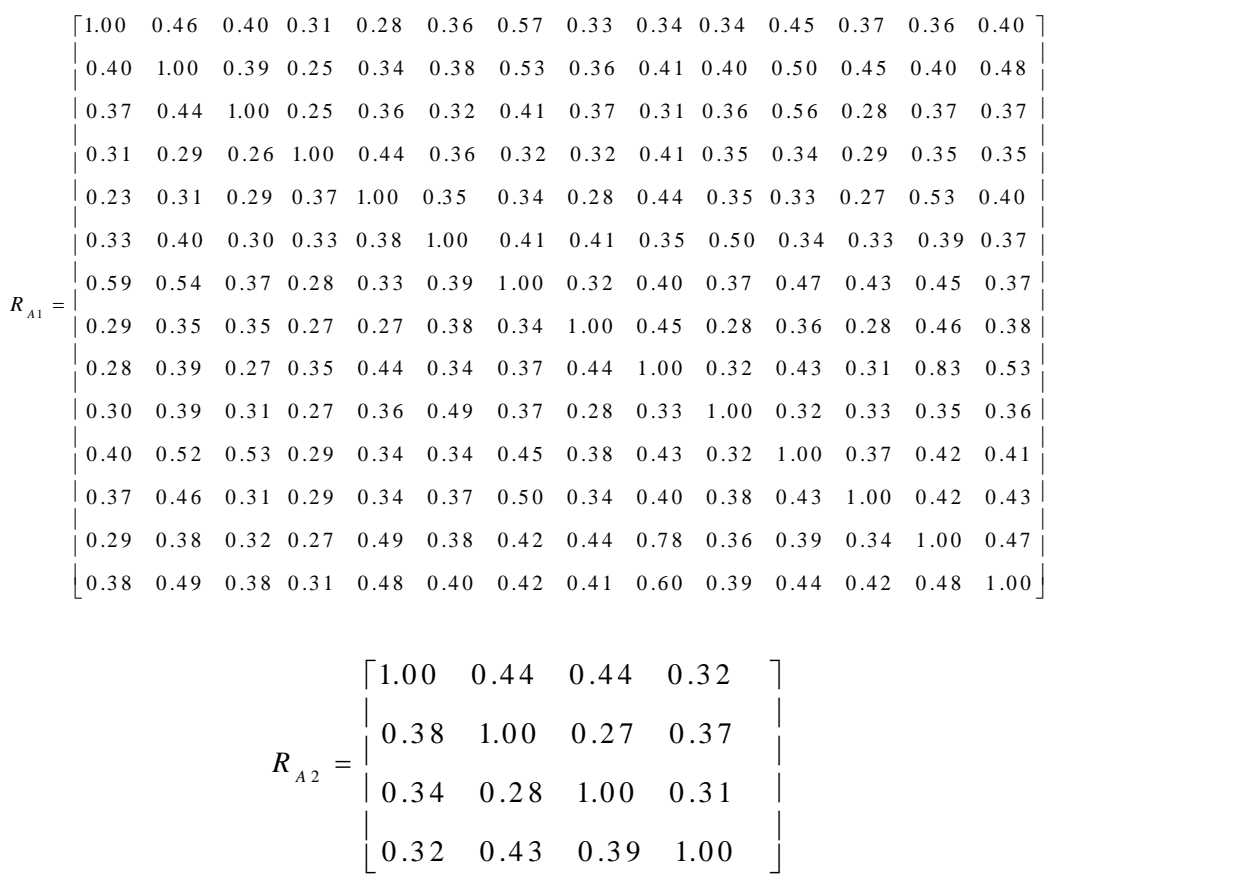

According to the above matrices and the definitions described earlier, the measures can be grouped into several clusters by threshold walue $=0.55$. The classification result is shown in Table 4, and the final measures of selection of the leading gndustries are identified as shown in Table 5.

Table 4. The classification of the representative measures

\begin{tabular}{|c|c|c|}
\hline Aspects & \begin{tabular}{l|l} 
Measures with each Cluster \\
\end{tabular} & Representative measures \\
\hline$A_{l}$ System rela & $\begin{array}{l}O C_{1} O C_{7} \\
O C_{2} \\
O C_{3}, O C_{11} \\
O C_{4} \\
O C_{5} \\
O C_{6} \\
O C_{8} \\
O C_{9,} O C_{13,} O C_{14} \\
O C_{10} \\
O C_{12}\end{array}$ & $\begin{array}{l}O C_{7} \\
O C_{2} \\
O C_{3} \\
O C_{4} \\
O C_{5} \\
O C_{6} \\
O C_{8} \\
O C_{14} \\
O C_{10} \\
O C_{12}\end{array}$ \\
\hline$A_{2}$ Service rel & \begin{tabular}{l|l} 
& $\begin{array}{l}O C_{15} \\
O C_{16} \\
O C_{17} \\
O C_{18}\end{array}$ \\
\end{tabular} & $\begin{array}{l}O C_{15} \\
O C_{16,} \\
O C_{17} \\
O C_{18} \\
\end{array}$ \\
\hline & Aspects & Criteria \\
\hline $\begin{array}{l}\text { Assessment of } \\
\text { online service } \\
\text { quality }\end{array}$ & $A_{l}$ System related & $\begin{array}{l}C_{1} \text { Efficiency } \\
C_{2} \text { Ease of navigation } \\
C_{3} \text { Flexibility } \\
C_{4} \text { Reliability } \\
C_{5} \text { Price knowledge } \\
C_{6} \text { Aesthetics } \\
C_{7} \text { Personalization } \\
C_{8} \text { Ownership conditions } \\
C_{9} \text { Ease of use } \\
C_{10} \text { Speed }\end{array}$ \\
\hline & $A_{2}$ Service related & $\begin{array}{l}C_{11} \text { Responsiveness } \\
C_{12} \text { Assurance } \\
C_{13} \text { Delivery } \\
\end{array}$ \\
\hline
\end{tabular}


\begin{tabular}{|l|l|l|}
\hline & & $C_{14}$ Customer service \\
\hline
\end{tabular}

The important degrees of the above sub-criteria weights are given with linguistic terms, i.e. VL, L, M, H, and VH, employed by four experts $E_{1}, E_{2}, E_{3}$ and $E_{4}$, as shown in Table 6.

Table 6 . The Grey weights given by four decision makers

\begin{tabular}{|l|l|l|l|l|l|}
\hline Criteria & $\mathrm{DM}_{1}$ & $\mathrm{DM}_{2}$ & $\mathrm{DM}_{3}$ & $\mathrm{DM}_{4}$ & $\otimes W_{j}$ \\
\hline$C_{1}$ & $\mathrm{H}[0.60,0.90]$ & $\mathrm{H}[0.60,0.90]$ & $\mathrm{M}[0.40,0.50]$ & $\mathrm{H}[0.60,0.90]$ & {$[0.55,0.80]$} \\
\hline$C_{2}$ & $\mathrm{H}[0.60,0.90]$ & $\mathrm{MH}[0.50,0.60]$ & $\mathrm{H}[0.60,0.90]$ & $\mathrm{M}[0.40,0.50]$ & {$[0.53,0.73]$} \\
\hline$C_{3}$ & $\mathrm{H}[0.60,0.90]$ & $\mathrm{H}[0.60,0.90]$ & $\mathrm{MH}[0.50,0.60]$ & $\mathrm{H}[0.60,0.90]$ & {$[0.58,0.83]$} \\
\hline$C_{4}$ & $\mathrm{MH}[0.50,0.60]$ & $\mathrm{VH}[0.90,1.00]$ & $\mathrm{VH}[0.90,1.00]$ & $\mathrm{H}[0.60,0.90]$ & {$[0.73,0.88]$} \\
\hline$C_{5}$ & $\mathrm{H}[0.60,0.90]$ & $\mathrm{H}[0.60,0.90]$ & $\mathrm{MH}[0.50,0.60]$ & $\mathrm{H}[0.60,0.90]$ & {$[0.58,0.83]$} \\
\hline$C_{6}$ & $\mathrm{H}[0.60,0.90]$ & $\mathrm{M}[0.40,0.50]$ & $\mathrm{M}[0.40,0.50]$ & $\mathrm{H}[0.60,0.90]$ & {$[0.50,0.70]$} \\
\hline$C_{7}$ & $\mathrm{H}[0.60,0.90]$ & $\mathrm{H}[0.60,0.90]$ & $\mathrm{MH}[0.50,0.60]$ & $\mathrm{MH}[0.50,0.60]$ & {$[0.55,0.75]$} \\
\hline$C_{8}$ & $\mathrm{H}[0.60,0.90]$ & $\mathrm{VH}[0.90,1.00]$ & $\mathrm{MH}[0.50,0.60]$ & $\mathrm{M}[0.40,0.50]$ & {$[0,60,0.75]$} \\
\hline$C_{9}$ & $\mathrm{H}[0.60,0.90]$ & $\mathrm{VH}[0.90,1.00]$ & $\mathrm{VH}[0.90,1.00]$ & $\mathrm{H}[0.60,0.90]$ & {$[0.75,0.95]$} \\
\hline$C_{10}$ & $\mathrm{H}[0.60,0.90]$ & $\mathrm{H}[0.60,0.90]$ & $\mathrm{MH}[0.50,0.60]$ & $\mathrm{H}[0.60,0.90]$ & {$[0.58,0.83]$} \\
\hline$C_{11}$ & $\mathrm{H}[0.60,0.90]$ & $\mathrm{VH}[0.90,1.00]$ & $\mathrm{VH}[0.901 .00]$ & $\mathrm{H}[0.60,0.90]$ & {$[0.75,0.95]$} \\
\hline$C_{12}$ & $\mathrm{MH}[0.50,0.60]$ & $\mathrm{H}[0.60,0.90]$ & $\mathrm{H}[0.60,0.90]$ & $\mathrm{H}[0.60,0.90]$ & {$[0.58,0.83]$} \\
\hline$C_{13}$ & $\mathrm{H}[0.60,0.90]$ & $\mathrm{VH}[0.90,1.00]$ & $\mathrm{MH}[0.50,0.60]$ & $\mathrm{H}[0.60,0.90]$ & {$[0.65,0.85]$} \\
\hline$C_{14}$ & $\mathrm{H}[0.60,0.90]$ & $\mathrm{VH}[0.90,1.00]$ & $\mathrm{VH}[0.90,1.00]$ & $\mathrm{VH}[0.90,1.00]$ & {$[0.83,0.98]$} \\
\hline
\end{tabular}

The normalized decision matrix is shown in Table 7.

Table 7. Normalized décision matrix

\begin{tabular}{lllllllllll}
\hline No. & $C_{1}$ & $C_{2}$ & $C_{3}$ & $C_{4}$ & $C_{5}$ & $C_{6}$ & $C_{7}$ & $C_{8}$ & $C_{9}$ \\
\hline$S_{1}$ & 0.23 & 0.42 & 0.88 & 0.98 & 0.36 & 0.33 & 0.99 & 1.00 & 0.86 \\
$S_{2}$ & 0.98 & 0.23 & 0.99 & 0.45 & 0.20 & 1.00 & 0.12 & 0.89 & 0.81 \\
$S_{3}$ & 0.44 & 0.33 & 0.43 & 0.33 & 0.08 & 0.28 & 0.98 & 0.67 & 1.00 \\
$S_{4}$ & 0.44 & 0.21 & 1.00 & 1.00 & 0.21 & 0.03 & 0.99 & 1.00 & 0.88 \\
$S_{5}$ & 0.13 & 0.42 & 0.39 & 0.09 & 0.39 & 0.01 & 0.79 & 0.87 & 0.91 \\
$S_{6}$ & 0.46 & 0.03 & 0.94 & 0.00 & 1.00 & 0.04 & 0.84 & 0.88 & 0.92 \\
$S_{7}$ & 0.17 & 0.46 & 1.00 & 0.07 & 0.01 & 0.06 & 1.00 & 1.00 & 0.74 \\
$S_{8}$ & 0.07 & 1.00 & 0.00 & 0.54 & 0.10 & 0.35 & 0.77 & 0.99 & 0.73 \\
$S_{9}$ & 1.09 & 0.18 & 0.74 & 0.00 & 0.94 & 0.26 & 0.00 & 0.98 & 0.81 \\
$S_{10}$ & 0.00 & 0.66 & 0.98 & 0.05 & 0.03 & 0.06 & 0.94 & 0.11 & 0.72 \\
$S_{11}$ & 0.05 & 0.70 & 0.93 & 0.03 & 0.00 & 0.02 & 0.96 & 0.44 & 0.47 \\
$S_{12}$ & 0.24 & 0.43 & 1.00 & 0.04 & 0.06 & 0.00 & 1.00 & 1.00 & 0.98 \\
$S_{I 3}$ & 0.26 & 0.51 & 0.98 & 0.02 & 1.00 & 0.08 & 0.91 & 0.99 & 0.00 \\
$S_{14}$ & 0.62 & 0.23 & 0.98 & 0.03 & 0.31 & 0.03 & 0.98 & 1.00 & 0.79 \\
$S_{15}$ & 0.31 & 0.35 & 1.00 & 0.00 & 0.00 & 0.00 & 0.98 & 0.95 & 0.74 \\
$S_{16}$ & 0.33 & 0.26 & 1.00 & 0.00 & 0.12 & 0.00 & 0.99 & 0.97 & 0.98 \\
$S_{17}$ & 0.98 & 0.00 & 1.00 & 0.03 & 0.01 & 0.00 & 0.62 & 0.86 & 0.90 \\
$S_{18}$ & 0.98 & 0.00 & 1.00 & 0.03 & 0.01 & 0.00 & 0.62 & 0.86 & 0.90 \\
\hline
\end{tabular}

In the next step, the Grey variables discussed in Section 3.3 is applied to transform Table 6 into Table 7 as explained by the following example. If the numeric rating is 0.05 , then its Grey variable is "VL". Therefore, the new pairwise comparison matrix is shown in Table 8: 
Table 8. Normalized decision matrix using Grey variables

\begin{tabular}{llllllll}
\hline & $C_{1}$ & $C_{2}$ & $C_{3}$ & $C_{4}$ & $C_{5}$ & $C_{6}$ & $C_{7}$ \\
\hline$A_{1}$ & $\mathrm{~L}$ & $\mathrm{M}$ & $\mathrm{H}$ & $\mathrm{VH}$ & $\mathrm{ML}$ & $\mathrm{ML}$ & $\mathrm{VH}$ \\
$A_{2}$ & $\mathrm{VH}$ & $\mathrm{L}$ & $\mathrm{VH}$ & $\mathrm{M}$ & $\mathrm{L}$ & $\mathrm{VH}$ & $\mathrm{L}$ \\
$A_{3}$ & $\mathrm{M}$ & $\mathrm{ML}$ & $\mathrm{M}$ & $\mathrm{ML}$ & $\mathrm{VL}$ & $\mathrm{L}$ & $\mathrm{VH}$ \\
$A_{4}$ & $\mathrm{M}$ & $\mathrm{L}$ & $\mathrm{VH}$ & $\mathrm{VH}$ & $\mathrm{L}$ & $\mathrm{VL}$ & $\mathrm{VH}$ \\
$A_{5}$ & $\mathrm{~L}$ & $\mathrm{M}$ & $\mathrm{ML}$ & $\mathrm{VL}$ & $\mathrm{ML}$ & $\mathrm{VL}$ & $\mathrm{H}$ \\
$A_{6}$ & $\mathrm{M}$ & $\mathrm{VL}$ & $\mathrm{VH}$ & $\mathrm{VL}$ & $\mathrm{VH}$ & $\mathrm{VL}$ & $\mathrm{H}$ \\
$A_{7}$ & $\mathrm{~L}$ & $\mathrm{M}$ & $\mathrm{VH}$ & $\mathrm{VL}$ & $\mathrm{VL}$ & $\mathrm{VL}$ & $\mathrm{VH}$ \\
$A_{8}$ & $\mathrm{VL}$ & $\mathrm{VH}$ & $\mathrm{VL}$ & $\mathrm{MH}$ & $\mathrm{L}$ & $\mathrm{ML}$ & $\mathrm{H}$ \\
$A_{9}$ & $\mathrm{VH}$ & $\mathrm{L}$ & $\mathrm{H}$ & $\mathrm{VL}$ & $\mathrm{VH}$ & $\mathrm{L}$ & $\mathrm{VL}$ \\
$A_{10}$ & $\mathrm{VL}$ & $\mathrm{H}$ & $\mathrm{VH}$ & $\mathrm{VL}$ & $\mathrm{VL}$ & $\mathrm{VL}$ & $\mathrm{VH}$ \\
$A_{11}$ & $\mathrm{VL}$ & $\mathrm{H}$ & $\mathrm{VH}$ & $\mathrm{VL}$ & $\mathrm{VL}$ & $\mathrm{VL}$ & $\mathrm{VH}$ \\
$A_{12}$ & $\mathrm{~L}$ & $\mathrm{M}$ & $\mathrm{VH}$ & $\mathrm{VL}$ & $\mathrm{VL}$ & $\mathrm{VL}$ & $\mathrm{VH}$ \\
$A_{13}$ & $\mathrm{~L}$ & $\mathrm{MH}$ & $\mathrm{VH}$ & $\mathrm{VL}$ & $\mathrm{VH}$ & $\mathrm{VL}$ & $\mathrm{VH}$ \\
$A_{14}$ & $\mathrm{H}$ & $\mathrm{L}$ & $\mathrm{VH}$ & $\mathrm{VL}$ & $\mathrm{ML}$ & $\mathrm{VL}$ & $\mathrm{VH}$ \\
$A_{15}$ & $\mathrm{ML}$ & $\mathrm{ML}$ & $\mathrm{VH}$ & $\mathrm{VL}$ & $\mathrm{VL}$ & $\mathrm{VL}$ & $\mathrm{VH}$ \\
$A_{16}$ & $\mathrm{ML}$ & $\mathrm{L}$ & $\mathrm{VH}$ & $\mathrm{VL}$ & $\mathrm{L}$ & $\mathrm{VL}$ & $\mathrm{VH}$ \\
$A_{17}$ & $\mathrm{VH}$ & $\mathrm{VL}$ & $\mathrm{VH}$ & $\mathrm{VL}$ & $\mathrm{VL}$ & $\mathrm{VL}$ & $\mathrm{H}$ \\
$S_{18}$ & 0.98 & 0.00 & 1.00 & 0.03 & 0.01 & 0.00 & 0.62 \\
\hline
\end{tabular}

The Grey variables of the above matrix are then rans formed into a Crey decision marix, as shown in Table 9:

Table 9. Part of the Grey decisionmatrix

\begin{tabular}{lccccccc}
\hline & $C_{1}$ & $C_{2}$ & $C_{3}$ & $C_{4}$ & $C_{3}$ & $C_{6}$ & $C_{7}$ \\
\hline$A_{1}$ & {$[0.10,0.30]$} & {$[0.40,0.50]$} & {$[0.60,0.90]$} & {$[0.90,1.00]$} & {$[0.30,0.40]$} & {$[0.30,0.40]$} & {$[0.90,1.00]$} \\
$A_{2}$ & {$[0.90,1.00]$} & {$[0.10,0.30]$} & {$[0.90,1.00]$} & {$[0.40,0.50]$} & {$[0,10,0.30]$} & {$[0.90,1.00]$} & {$[0.10,0.30]$} \\
$A_{3}$ & {$[0.40,0.50]$} & {$[0.30,0.40]$} & {$[0.40,0.50]$} & {$[0.30,0.40]$} & {$[0.00,0.10]$} & {$[0.10,0.30]$} & {$[0.90,1.00]$} \\
$A_{4}$ & {$[0.40,0.50]$} & {$[0.10,0.30]$} & {$[0.90, .00]$} & {$[0.90,1.00]$} & {$[0.10,0.30]$} & {$[0.00,0.10]$} & {$[0.90,1.00]$} \\
$A_{5}$ & {$[0.10,0.30]$} & {$[0.40,0.50]$} & {$[0.30,0.40]$} & {$[0.00,0.10]$} & {$[0.30,0.40]$} & {$[0.00,0.10]$} & {$[0.60,0.90]$} \\
$A_{6}$ & {$[0.40,0.50]$} & {$[0.00,0.10]$} & {$[0.90,1.00]$} & {$[0.00,0.10]$} & {$[0.90,1.00]$} & {$[0.00,0.10]$} & {$[0.60,0.90]$} \\
$A_{7}$ & {$[0.10,0.30]$} & {$[0.40,0.50]$} & {$[0.90,1.00]$} & {$[0.00,0.10]$} & {$[0.00,0.10]$} & {$[0.00,0.10]$} & {$[0.90,1.00]$} \\
$A_{8}$ & {$[0.00,0.10]$} & {$[0.90,1.00]$} & {$[0.00,0.10]$} & {$[0.50,0.60]$} & {$[0.10,0.30]$} & {$[0.30,0.40]$} & {$[0.60,0.90]$} \\
$A_{9}$ & {$[0.90,1.00]$} & {$[0.10,0.30]$} & {$[0.60,0.90]$} & {$[0.00,0.10]$} & {$[0.90,1.00]$} & {$[0.10,0.30]$} & {$[0.00,0.10]$} \\
$A_{10}$ & {$[0.00,0.10]$} & {$[0.60,0.90]$} & {$[0.90,100]$} & {$[0.00,0.10]$} & {$[0.00,0.10]$} & {$[0.00,0.10]$} & {$[0.90,1.00]$} \\
$A_{11}$ & {$[0.00,0.10]$} & {$[0.60,0.90]$} & {$[0.90,1.00]$} & {$[0.00,0.10]$} & {$[0.00,0.10]$} & {$[0.00,0.10]$} & {$[0.90,1.00]$} \\
$A_{12}$ & {$[0.10,0.30]$} & {$[0.40,0.50]$} & {$[0.90,1.00]$} & {$[0.00,0.10]$} & {$[0.00,0.10]$} & {$[0.00,0.10]$} & {$[0.90,1.00]$} \\
$A_{13}$ & {$[0.10,0.30]$} & {$[0.50,0.60]$} & {$[0.90,1.00]$} & {$[0.00,0.10]$} & {$[0.90,1.00]$} & {$[0.00,0.10]$} & {$[0.90,1.00]$} \\
$A_{14}$ & {$[0.60,0.90]$} & {$[0.10,0.30]$} & {$[0.90,1.00]$} & {$[0.00,0.10]$} & {$[0.30,0.40]$} & {$[0.00,0.10]$} & {$[0.90,1.00]$} \\
$A_{15}$ & {$[0.30,0.40]$} & {$[0.30,0.40]$} & {$[0.90,1.00]$} & {$[0.00,0.10]$} & {$[0.00,0.10]$} & {$[0.00,0.10]$} & {$[0.90,1.00]$} \\
$A_{16}$ & {$[0.30,0.40]$} & {$[0.0,0.30]$} & {$[0.90,1.00]$} & {$[0.00,0.10]$} & {$[0.10,0.30]$} & {$[0.00,0.10]$} & {$[0.90,1.00]$} \\
$A_{17}$ & {$[0.90,1.00]$} & {$[0.00,0.10]$} & {$[0.90,1.00]$} & {$[0.00,0.10]$} & {$[0.00,0.10]$} & {$[0.00,0.10]$} & {$[0.60,0.90]$} \\
$\otimes W{ }_{j}$ & {$[0.58,0.83]$} & {$[0.65,0.85]$} & {$[0.48,0.63]$} & {$[0.53,0.73]$} & {$[0.53,0.73]$} & {$[0.63,0.84]$} & {$[0.58,0.83]$} \\
\hline
\end{tabular}

Followng the resulting Grey weighted decision matrix can be derived based on Table 9 and the weights identified before, and the values of ideal leading industry $A^{\max }$ are shown betow for our illustration.

$A^{\mathrm{m} / \mathrm{ax}}=\{[0.52,0.83],[0.59,0.85],[0.43,0.63],[0.48,0.73],[0.48,0.73],[0.57,0.84],[0.52,0.83]$,

$[0.63,0.85],[0.52,0.83]\}$

Then the Grey possibility value for each industry is given below: 


$$
\begin{aligned}
& P\left(A_{1} \leq A^{\mathrm{max}}\right)=0.1401 ; P\left(A_{2} \leq A^{\mathrm{max}}\right)=0.1536 ; P\left(A_{3} \leq A^{\mathrm{max}}\right)=0.1732 ; P\left(A_{4} \leq A^{\mathrm{max}}\right)=0.1667 \\
& P\left(A_{5} \leq A^{\mathrm{max}}\right)=0.1924 ; P\left(A_{6} \leq A^{\mathrm{max}}\right)=0.1867 ; P\left(A_{7} \leq A^{\mathrm{max}}\right)=0.1952 ; P\left(A_{8} \leq A^{\mathrm{max}}\right)=0.1714 ; \\
& P\left(A_{9} \leq A^{\mathrm{max}}\right)=0.1851 ; P\left(A_{10} \leq A^{\mathrm{max}}\right)=0.2164 ; P\left(A_{11} \leq A^{\mathrm{max}}\right)=0.2122 ; P\left(A_{12} \leq A^{\mathrm{max}}\right)=0.1941 ; \\
& P\left(A_{13} \leq A^{\mathrm{max}}\right)=0.1962 ; P\left(A_{14} \leq A^{\mathrm{max}}\right)=0.1772 ; P\left(A_{15} \leq A^{\mathrm{max}}\right)=0.1934 ; P\left(A_{16} \leq A^{\mathrm{max}}\right)=0.1920 ; \\
& P\left(A_{17} \leq A^{\mathrm{max}}\right)=0.1996
\end{aligned}
$$

The industries are prioritized based on the Grey possibility values:

$$
A_{1}>A_{2}>A_{4}>A_{8}>A_{3}>A_{14}>A_{9}>A_{6}>A_{16}>A_{5}>A_{15}>A_{12}>A_{7}>A_{13}>A_{17}>A_{11}>A_{10}
$$

\section{Conclusions}

This research is focused on identify the selection standards of leading industries in China, which could be the guideline for the harmonious development of regional economy and environment. Grey approach is employed to identify the selection standards of leading industries.

According to the criteria weights derived from this section earlier, the relative top three important measures to select the leading industries in China are (1) dust emissions per enterprise; (2) product sales ratio and (3) employment-absorption rate. As such, the Chinese government shall pay more attention to these measures, when make the decision of the selection of the regional leading industries,

Based on the results of this research, the processing of foods, coal mining and dressing, manufacture of foods, production and stpply of etectrieity, gas and water, manufacture of non-metallic mineral products, manufacture of beverages and mining and processing of nonferrous metal ores should be the peichities of the regional leading industries for the city selected for the empirical study.

\section{References}

[1] G. Chen, "Selection meaning, principle) and benchmark", Theoretical Exploration, (2004), pp. 5253.

[2] Y. Dang, and S. Liu, "Foyndation and selection for evaluation index of agriculture leading industry", Journal of Agro- teehnical Economics, vol. 1, (2000), pp. 6-9.

[3] J. L. Deng, "Contro/problem of grey systems", Systems and Control Letters", vol. 1, no. 5, (1982), pp. 288-294.

[4] J. Du, B. Yu. and X. Yao, "Selection of leading industries for coal resource cities based on coupling coordination of industry's technological innovation", International Journal of Mining Science and Technology, vol. 22. (2013), pp. 317-321.

[5] C. Faircheallaihg, "Economic base and employment structure in Northern territory mining towns", Resource Communities: Settlement and Workforces Issues, (1998), pp. 221-236.

[6] V. Henderson, "Urbanization in China: Policy Issues and Options", A report from China Economic Research and Advisory Programme, (2009), pp. 3-10.

[7] G. Hinson, "Sustainable development policies in Canada's mining sector: an overview of government and industry efforts", Environment Science Policy, vol. 3, (2000), pp. 110-115.

[8] D. S. Houston, "Long-distance community: a new approach to mining in Australia", Geographical Journal, vol. 3, (1993), pp. 281-290.

[9] A. Guan, and Y. Wang, "The analysis of choosing standard of regional pillar industry", Statistical Research, vol. 12, (2002), pp. 37-40.

[10] K. Guo, "On newly leading industries in the new period of industrialization in China", China Industry Economy, vol. 2, no. 2, (2003), pp. 5-8. 
[11] K. Guo, "On newly leading industries in the new period of industrialization in China", China Industry Economy, vol. 2, no. 2, (2003), pp. 5-8.

[12] L. Ma, "Research on choosing leading industry in Bengbu city", Journal of Anhui Science and Technology University, vol. 27, no. 3, (2013), pp. 99-103.

[13] J. Woetzel, "Preparing for China's Urban Billion”, McKinsey Global Institute, McKinsey and Company, vol. 3, (2008).

[14] Q. Meng, "Selection and cultivation of area characteristic industry", Inquiry into Economic Issues vol. 9, (2003), pp. 35-39.

[15] Tong, "The research on the benchmark of the choice of leading industry based on the shift-sharemethod", Economic Geography, vol. 9, no. 5, (2007), pp. 733-738.

[16] L. Wang, "Discussion on selection benchmark analysis of area leading industry", Coal Technology, vol. 23, no. 8, (2004), pp. 110-111.

[17] Q. Xu, "The analysis for three chief standards of leading industry selection”, Journal of Liaoyang Petrochemical College, vol. 17, no. 1, (2001), pp.69- 71.

[18] K. Zhang, "Structure to evaluate system of regional leading industry", Science and Technology Progress and Policy, vol. 8, (2004), pp. 7-9.

[19] S. Zhang, "Analysis of area leading industry selection”, Economic Problems (2001) pp. 22-24.

[20] Y. Zhao and X. Yu, "Study on the selection of leading industries for Chong ing based on inputoutput and DEA analysis", Journal of Chongqing Technology and Business Unversity, vol. 28, no. 3, (2011), pp. 33-36.

[21] Z. Zhou, "Policy of cultivating stratagem industry. Research on Financial and Economic Issues", vol. 1, (1992), pp. 18-23.

[22] Y. Zhu, "Selection benchmark analysis of area leading industry Shanghai Economic Forum, vol. 11, (2003), pp. 24-26.

[23] Y. Wang, D. M. Hernandez, and S. M. Minor, Web aesthetics effects on perceived online service quality and satisfaction in an e-tail environment: the moderating role of purchase task", Journal of Business Research, vol. 63, (2010) pp. 935-942.

[24] D. X. Ding, J. P. Hu, and L. O. Sheng, "E-SELFQUAL: a scale for measuring online self-service quality", Journal of Business Research, vol. 64, 2011), pp. 508-515.

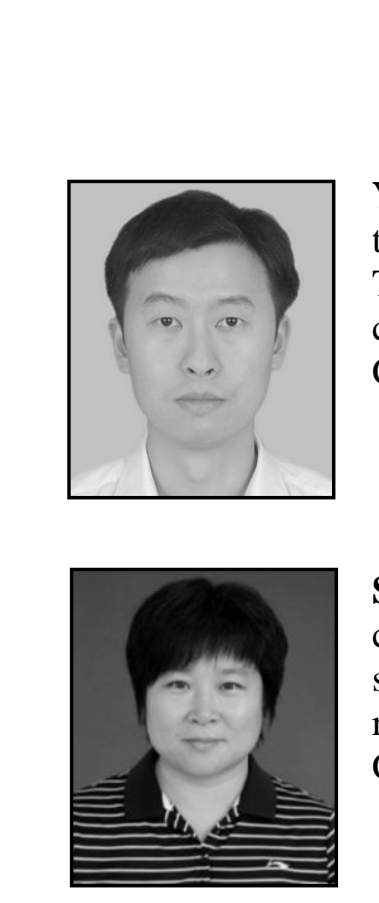

\section{Authors}

Yonglin Liang, he received his Master of Software Engineering in the college of Software from Hua zhong University of Science and Technology. Since 2009 he is a lecturer of Shao guan University. His current research interests include Recommender System and Human Computer Interaction.

Shumei Liu, she received her master's degree in Engineering in the college of Computer Science from Shan Xi University .Since 2007 she is an associate professor of Hengshui University. Her current research interests include Education Informatization and Human Computer Interaction. 